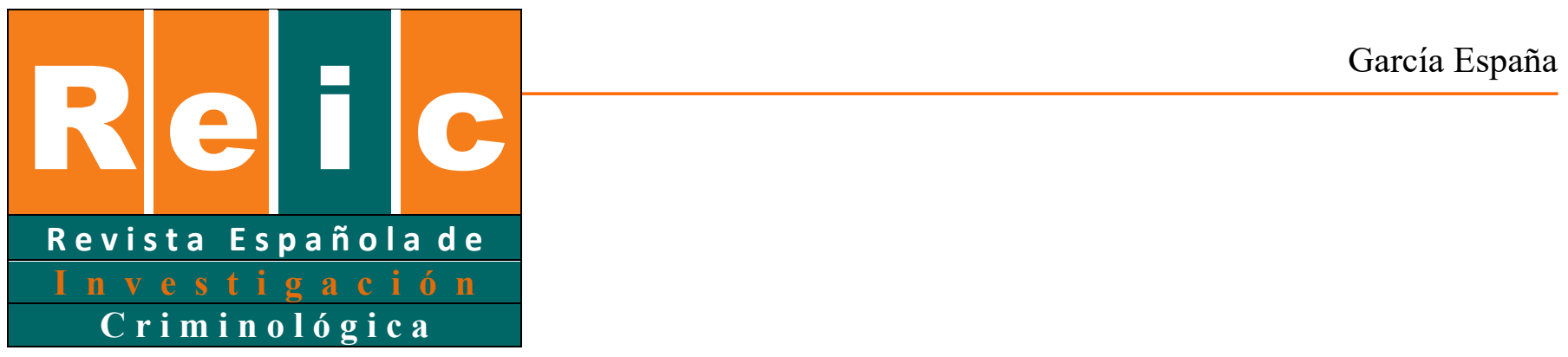

\title{
Editorial
}

Elisa García España

Editora-Jefa REIC

Universidad de Málaga

\section{La REIC: balance, novedades y retos}

Desde la editorial de la Revista Española de Investigación Criminológica presentamos un nuevo número, compartiendo con los lectores el balance anual de 2019 , las novedades que ofrecemos para los años venideros y los retos que nos proponemos para este nuevo año.

Pero antes de empezar con todo ello, quisiera agradecer a los autores que han mandado sus trabajos por el interés en publicar en la REIC y a los revisores su desinteresada labor con la que sin duda han mejorado los trabajos presentados. El equipo editorial trabaja para que el proceso de publicación sea ágil y amable. Ayuda a ello contar con un software Open Journal Systems con el que se gestionan los envíos de los artículos y se facilita la comunicación con los autores y revisores. También la nueva interfaz de la página web de la REIC y su actualizado diseño facilitan el acceso a la información requerida. Pero sin duda es la labor paciente, rigurosa y afable de la asistente editorial, Bertha Prado, la que aporta especial sostenibilidad a esta empresa.

1. El balance de 2019 puede resumirse con los siguientes datos: se han recibido 28 artículos para su revisión de los cuales 6 han sido rechazos iniciales y 13 han sido publicados,

Revista Española de Investigación Criminológica

Editorial, Número 18 (2020)

https://doi.org/10.46381/reic.v18i0.359

www.criminologia.net

ISSN: 1696-9219 
de los cuales 2 han sido en inglés. La mitad de los artículos enviados a la REIC han visto finalmente la luz en nuestra revista.

Este balance es muy similar al de otros años, aunque con un ligero aumento en el número de artículos publicados, como puede verse en la siguiente tabla.

Tabla 1: Balance REIC 2016-2018

\begin{tabular}{|c|c|c|c|c|}
\hline Años & $\begin{array}{c}\text { Manuscritos } \\
\text { recibidos }\end{array}$ & Rechazos iniciales & $\begin{array}{c}\text { Rechazo tras } \\
\text { revisión }\end{array}$ & Publicados \\
\hline 2016 & 35 & 13 & 11 & 6 \\
\hline 2017 & 30 & 10 & 5 & 5 \\
\hline 2018 & 28 & 10 & 1 & 13 \\
\hline
\end{tabular}

Todo esto deja ver el trabajo que hay no solo por parte del equipo editorial, sino también de los editores asociados, de la asesoría técnica, de los revisores y de los autores que eligen nuestra revista. El resultado final es satisfactorio aunque mejorable. Nuestra proyección europea debe seguir afianzándose. Precisamente por ello hemos pensado en diversas estrategias a considerar, siendo una de ellas las que presentamos a continuación como novedad.

2. En 2019, en el empeño por mantener un camino de excelencia emprendido desde la creación de la REIC, asumimos el reto de consolidar la internacionalización de la revista. A la vista del balance anterior y para tratar de alcanzar ese objetivo, presentamos como novedad a partir de este año la posibilidad de que los grupos de trabajo de la SEIC propongan números especiales relacionados con la temática de sus grupos, fruto de su trabajo o de eventos académicos que organicen. La coordinación de dichos números recaerá sobre las mismas personas que coordinan los grupos de trabajo o en quien el grupo designe. Se publicará como máximo un número especial y temático al año para evitar la sobrecarga de trabajo en el equipo editorial. 
Actualmente está en marcha ya el primer número especial para el año 2020 sobre "Immigration, Crimen and Punishment" coordinado por José Ángel Brandariz, Cristina Fernández Bessa y yo misma, todos miembros del grupo de trabajo de la SEIC "Inmigración y control social". Este número especial es fruto del Seminario internacional celebrado en Málaga en mayo de 2019 sobre "Immigration, Crime, Citizenship in troubled times" que se organizó en el marco del grupo de trabajo "Immigration, Crime and Citizens" de la European Society of Criminology (ESC). Este seminario, organizado por el grupo de trabajo de la SEIC sobre Inmigración y control social y el OCSPI (Observatorio criminológico del sistema penal ante la inmigración) pretendía por una parte reactivar el grupo de trabajo de la ESC y, por otra, dar a conocer el trabajo que la Criminología española está realizando en la visibilización de situaciones migratorias de vulnerabilidad y exclusión, su aporte científico encaminado a mejorar la racionalidad legislativa penal y penitenciaria, y su contribución en la planificación de estrategias de inclusión pre- y post- delictivo.

Esta iniciativa es solo un ejemplo con el que esperamos animar al resto de los grupos de trabajo de la SEIC a publicar números monográficos. La publicación en inglés no es una exigencia para la edición de números especiales, pero es una forma de dar a conocer la REIC, ofreciendo esta publicación como una opción a considerar para potenciales autores de otros países no hispanoparlantes.

3. El reto de este año es muy concreto y tiene que ver con un mayor impacto y mejores indicadores de calidad que hagan atractiva la REIC para el envío de trabajos en inglés y castellano. En este sentido ya hay un camino recorrido de muchos años. No obstante, aún tenemos objetivos que alcanzar, siendo uno de ellos a medio plazo la indexación de la REIC en SCOPUS, una de las bases de datos más consultadas a nivel internacional por investigadores de todo el mundo. Precisamente, para conseguir dicho objetivo, este año hemos empezado a gestionar la asignación de un código DOI (Digital Object Identifier) para facilitar la localización de los artículos publicados en la REIC y requisito indispensable para poder estar indexados en SCOPUS.

Revista Española de Investigación Criminológica

Editorial, Número 18 (2020)

https://doi.org/10.46381/reic.v18i0.359

www.criminologia.net

ISSN: 1696-9219 
Con la ilusión de empezar un nuevo año, no nos queda más que renovar nuestro compromiso de esfuerzo y dedicación para con nuestros lectores y autores que confían en la REIC.

Revista Española de Investigación Criminológica

Editorial, Número 18 (2020)

https://doi.org/10.46381/reic.v18i0.359

www.criminologia.net

ISSN: 1696-9219 